
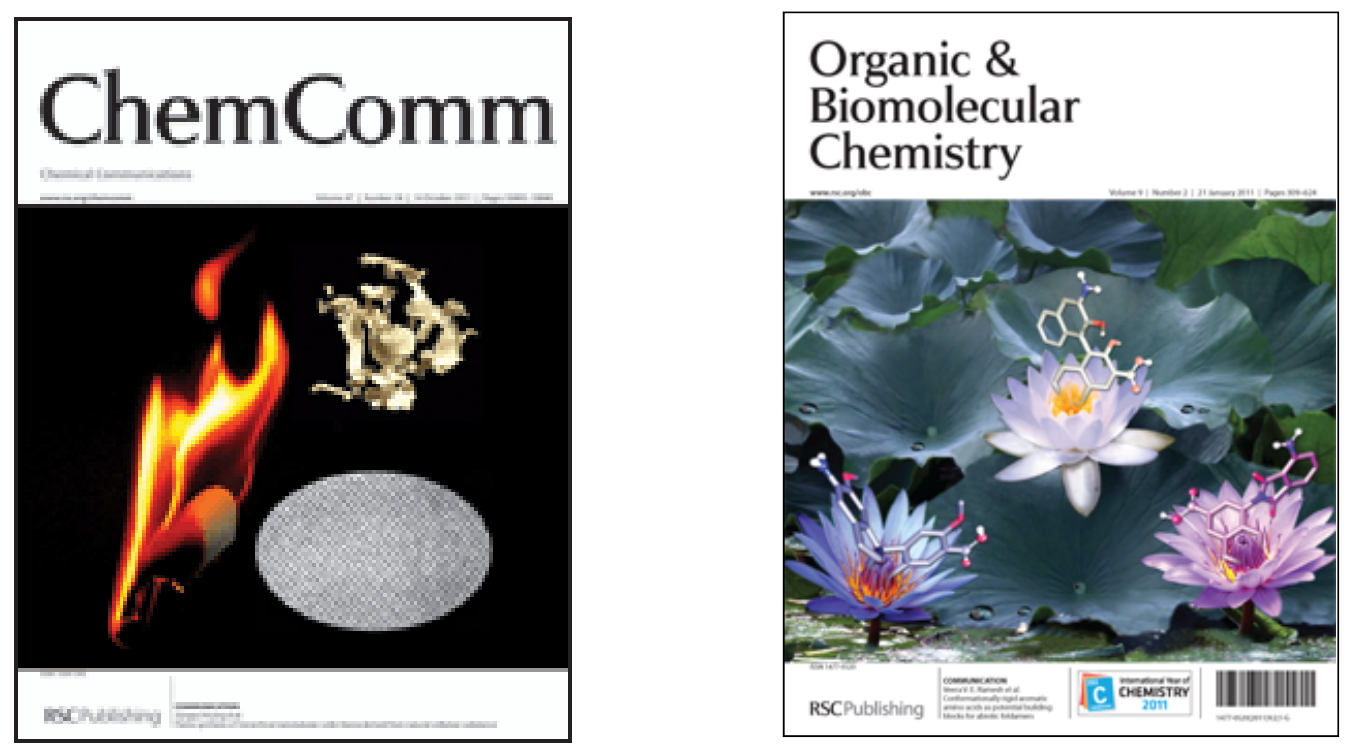

This article is part of the Organocatalysis web themed issue

Guest editors: Professors Keiji Maruoka, Hisashi Yamamoto, Liu-Zhu Gong and Benjamin List

All articles in this issue will be gathered together online at www.rsc.org/organocatalysis

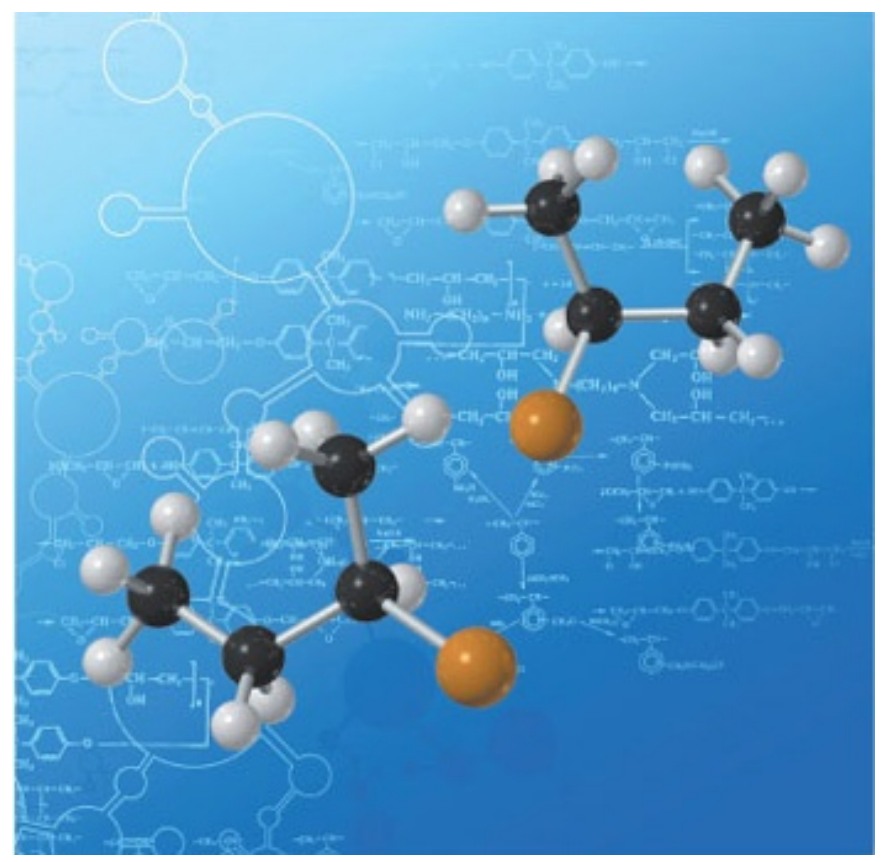




\section{Poly(methylhydrosiloxane)-supported chiral imidazolinones: new versatile, highly efficient and recyclable organocatalysts for stereoselective Diels-Alder cycloaddition reactions $\dagger \ddagger$}

\author{
Stefania Guizzetti, ${ }^{a}$ Maurizio Benaglia ${ }^{* a}$ and Jay S. Siegel ${ }^{* b}$ \\ Received 19th December 2011, Accepted 26th January 2012 \\ DOI: $10.1039 / \mathrm{c} 2 \mathrm{cc17919a}$

\begin{abstract}
Poly(methylhydrosiloxane) (PMHS) supported organic catalysts promoted the Diels-Alder reaction of dienes with $\alpha, \beta$-unsaturated aldehydes, also in pure water, in yields and enantiomeric excesses comparable to those observed with the non-supported catalysts (up to $93 \%$ ee). Recycling of the catalysts was performed with no loss of enantioselectivity for at least five reaction cycles.
\end{abstract}

Supporting catalysts and reagents on polymer backbones offer several engineering advantages with respect to the goals of "Green" chemistry. ' In systems like grafted polyHDMS, where the final macromolecular properties strongly reflect the nature of the grafts, one can anticipate control over solubility, isolability and even stability through judicious tuning of graft composition and proportion. In the area of "Organocatalysis", these tailored macromolecules maintain low equivalent weight and good solubility characteristic of lower molecular weight "homogenous" embodiments while providing easy catalyst confinement and recovery methods, which address separation, recycling and waste management issues. ${ }^{2}$ In the present context, grafting of imidazolium based catalysts (ala MacMillan) to polyHDMS produces catalysts with sustainable high-level performance across a variety of conditions.

The immobilization of organocatalysts seems particularly attractive, because these metal free systems obviate classical leaching problems and lend themselves to batch or flow processes. ${ }^{3}$ In this context the choice of the support plays a crucial role. ${ }^{4}$ Polymers of discreet solubility can be extremely convenient because they allow us to realize a "monophase" (that is, homogeneous) catalysis while still enjoying the advantage of biphase separations. ${ }^{5,6}$ We have recently turned our attention to polymethylhydrosiloxane (PMHS) that presents several positive features such as low cost, commercial availability, easy fuctionalization, and very favourable solubility profile. Indeed, PMHS is soluble in many organic solvents

${ }^{a}$ Dipartimento di Chimica Organica e Industriale,

Università di Milano, via Venezian 21, 20133, Milano, Italy.

E-mail: Maurizio.Benaglia@unimi.it; Fax: +390250314159;

Tel: +390250314171

${ }^{b}$ Organisch-Chemisches Institut, Universität Zürich,

Winterthurerstrasse 190, CH-8057 Zürich, Switzerland.

E-mail: jss@oci.uzh.ch; Fax: +410446356888; Tel: +410446354281

$\dagger$ This article is part of the joint ChemComm-Organic \& Biomolecular Chemistry 'Organocatalysis' web themed issue.

$\ddagger$ Electronic supplementary information (ESI) available. See DOI: $10.1039 / \mathrm{c} 2 \mathrm{cc} 17919 \mathrm{a}$ and insoluble in a few other solvents, like hexanes, thus allowing us to run a catalyzed reaction under homogeneous conditions and to isolate and recover the catalyst as if it were bound to an insoluble polymer. PMHS is a well known, cheap, atoxic, widely used reducing agent, ${ }^{7}$ however quite surprisingly its use as support for the immobilization of chiral catalysts remained almost unexplored. Only recently one of us reported the use of PMHS-anchored cinchona alkaloid derivatives to obtain recyclable ligands for the Sharpless dihydroxylation reaction. ${ }^{8}$

Here we describe for the first time the synthesis of PMHSsupported chiral organic catalysts derived from MacMillan's imidazolidin-4-ones and a study of their behaviour in the stereoselective Diels-Alder cycloaddition.

The protonated phenylalanine-derived imidazolidinone $\mathbf{1}$ developed by MacMillan ${ }^{9}$ has found widespread use in a number of relevant organocatalytic processes. Given its popularity, it is not surprising that it has been covalently immobilized on different supports. ${ }^{10-15}$

Despite this variety of proposed solutions, however, the development of an easily available, inexpensive, recyclable and truly chemical and stereochemical efficient MacMillan catalyst still has to be realized. Among the major drawbacks still to be properly addressed and solved we can mention the lower enantioselectivities with respect to that of the non-supported system and the issue of the recyclability.

In principle, the immobilization of imidazolidin-4-ones such as 1 (Fig. 1) can be performed using two different handles for polymer attachment: the amide nitrogen at position 3 , and the aryl residue at the stereogenic centre; both of them were explored as connecting points to PMHS in this work.§

Starting from $(S)$-tyrosine methyl ester hydrochloride, imidazolidinone 2 was easily obtained in $77 \%$ overall yield by $\mathrm{N}$-butyl amide formation, treatment with acetone, and reaction with allyl bromide in acetonitrile in the presence of $\mathrm{Cs}_{2} \mathrm{CO}_{3}$. The introduction of the allyl double bond was instrumental to
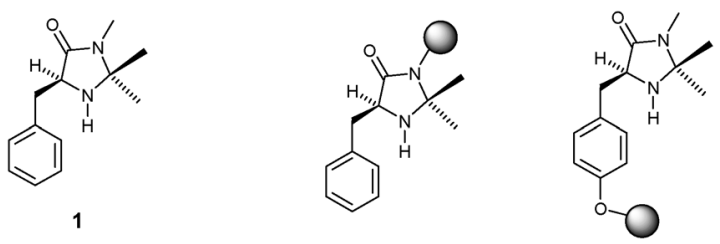

Fig. 1 MacMillan catalyst. 


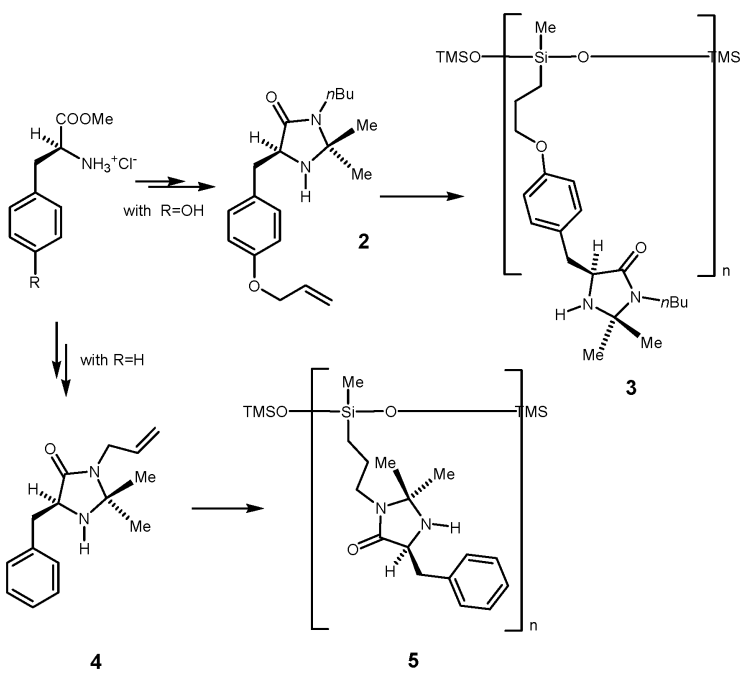

Scheme 1 Synthesis of PMHS-supported chiral imidazolinones.

perform catalyst immobilization by platinum catalyzed hydrosilylation, a reaction that led to the isolation of the PMHSsupported catalyst 3 in $90 \%$ yield (Scheme 1). ${ }^{8}$

On the other hand the condensation of $(S)$-phenyl alanine with allyl amine followed by reaction with acetone gave in $83 \%$ yield the imidazolinone 4 that was anchored to PMHS to give 5. Conversion of these compounds to the catalytically active species involved the addition of an equimolar amount of a protic acid. In situ protonated supported catalysts and pre-formed catalysts were both investigated and their behavior was compared.

The Diels-Alder cycloaddition of cyclopentadiene ( 5 mol equiv.) with trans-cinnamaldehyde (1 mol equiv.) carried out in the presence of $0.1 \mathrm{~mol}$ equiv. of various salts of $\mathbf{3}$ and $\mathbf{5}$ at different temperatures was used to evaluate the performance of the supported catalysts (Table 1). Yields were determined based on the isolated products; endo/exo ratios were determined by ${ }^{1} \mathrm{H}$ NMR analysis of the crude products and confirmed based on

Table 1 Enantioselective Diels-Alder reaction catalyzed by catalyst 5

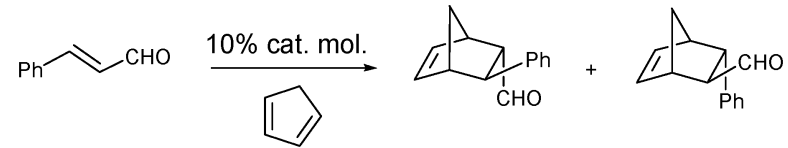

\begin{tabular}{|c|c|c|c|c|c|}
\hline Entry $^{a}$ & Acid & Solvent & $\begin{array}{l}\text { Yield }^{b} \\
(\%)\end{array}$ & $\begin{array}{l}\text { exo/endo } \\
(\%)\end{array}$ & $\begin{array}{l}\text { exo ee } \\
(\text { endo ee })^{d} \\
(\%)\end{array}$ \\
\hline $1^{e}$ & $\mathrm{HCl}$ & $95: 5 \mathrm{MeOH}: \mathrm{H}_{2} \mathrm{O}$ & 51 & $48 / 52$ & $55(45)$ \\
\hline $2^{e}$ & $\mathrm{HCl}$ & neat & 67 & $51 / 49$ & $51(23)$ \\
\hline $3^{e}$ & TFA & $95: 5 \mathrm{MeOH}: \mathrm{H}_{2} \mathrm{O}$ & 85 & $52 / 48$ & $84(80)$ \\
\hline $4^{e}$ & TFA & neat & 98 & $52 / 48$ & $83(82)$ \\
\hline 5 & TFA & neat & 48 & $52 / 48$ & $86(83)$ \\
\hline 6 & $\mathrm{HBF}_{4}$ & $95: 5 \mathrm{MeOH}: \mathrm{H}_{2} \mathrm{O}$ & 67 & $52 / 48$ & $91(91)$ \\
\hline 7 & $\mathrm{CH}_{3} \mathrm{SO}_{3} \mathrm{H}$ & $95: 5 \mathrm{MeOH}: \mathrm{H}_{2} \mathrm{O}$ & 31 & $52 / 48$ & $84(82)$ \\
\hline 8 & $\mathrm{CF}_{3} \mathrm{SO}_{3} \mathrm{H}$ & $95: 5 \mathrm{MeOH}: \mathrm{H}_{2} \mathrm{O}$ & 45 & $52 / 48$ & $80(79)$ \\
\hline 9 & $\mathrm{HBF}_{4}$ & neat & 33 & $58 / 42$ & $61(61)$ \\
\hline 10 & $\mathrm{HBF}_{4}$ & $85: 15$ DCM : $\mathrm{H}_{2} \mathrm{O}$ & 45 & $48 / 52$ & $91(93)$ \\
\hline 11 & $\mathrm{HBF}_{4}$ & $95: 5 \mathrm{CH}_{3} \mathrm{CN}: \mathrm{H}_{2} \mathrm{O}$ & 65 & $55 / 45$ & $92(93)$ \\
\hline
\end{tabular}

${ }^{a}$ Reaction run at $0{ }^{\circ} \mathrm{C} .{ }^{b}$ Yields determined after chromatographic purification. ${ }^{c}$ Diastereoisomeric ration determined by NMR on the crude reaction mixture. ${ }^{d}$ Enantiomeric excess determined by HPLC on the alcohols obtained by $\mathrm{NaBH}_{4}$ reduction of adducts. ${ }^{e}$ Reaction run at $25^{\circ} \mathrm{C}$. the isolated compounds; ees were obtained by HPLC analysis. As can be seen from the reported data, roughly $50: 50$ mixtures of endo and exo cycloadducts were typically obtained.

Preliminary experiments with PMHS-supported catalyst 5 showed that preformed salts gave better results than in situ prepared catalysts. The use of trifluoroacetic acid led to chemically and stereochemically more efficient processes than with $\mathrm{HCl}$ (see entries 3-4vs entries 1-2 of Table 1). However in a $95 / 5 \mathrm{MeOH} /$ water mixture as reaction solvent best results were obtained with $\mathrm{HBF}_{4}$ salts. Under the best conditions (entry 6) the cycloadduct was isolated in $67 \%$ yield as a $52 / 48$ mixture of exo and endo isomers, both having $91 \%$ ee. PMHSimmobilized catalyst 3 , derived from $(S)$-tyrosine, catalyzed the Diels-Alder reaction with lower stereoselectivity. || Noteworthily tetrafluoroborate salt of PMHS-supported imidazolinone 5 performed well in different solvent systems, promoting the cycloaddition in up to $93 \%$ enantioselectivity also in aqueous dichloromethane or acetonitrile.

The behavior of chiral imidazolinone 5 in aqueous reaction media was further investigated (Table 2). It was discovered that the PMHS-supported $\mathrm{HBF}_{4}$ salt of $\mathbf{5}$ promoted the cycloaddition in different methanol/water mixtures always with enantioselectivities higher than $90 \%$. Even at $25{ }^{\circ} \mathrm{C}$ the product was isolated in $87 \%$ yield and $90 \%$ ee. The reaction in pure methanol proceeded with a good stereoselectivity but definitely in lower yield (entry 7 , Table 2). With dichloromethane best results were observed with a $1 / 1 \mathrm{DCM} /$ water mixture, when the two isomers of the cycloadduct were isolated in $91 \%$ and $95 \%$ ee (entry 9 , Table 2). Remarkably PMHS-supported catalyst $\mathbf{5}$ promoted the Diels-Alder reaction in pure water. In this medium, not only at $0{ }^{\circ} \mathrm{C}$ but even at room temperature the use of $\mathrm{HBF}_{4}$ salt of $\mathbf{5}$ led to the formation of the cycloadducts in almost quantitative yield and enantioselectivities constantly higher than $90 \%$ (entries $10-11$, Table 2 ). ${ }^{16}$

In addition to facilitating the separation of the catalyst from the reaction products, catalyst immobilization on a polymer should allow simple recovery and recycling. In this work, the separation of the catalyst was easily obtained by concentrating the reaction mixture under vacuum, dissolving the residue in a very small amount of dichloromethane ( $2 \mathrm{~mL} \mathrm{~g}^{-1}$ of catalyst), and adding hexanes to the mixture

Table 2 Enantioselective Diels-Alder cycloaddition promoted by catalyst $\mathbf{5}$ in aqueous reaction medium

\begin{tabular}{|c|c|c|c|c|c|}
\hline Entry $^{a}$ & Acid & Solvent & $\begin{array}{l}\text { Yield } \\
(\%)\end{array}$ & $\begin{array}{l}\text { exo/endo }{ }^{b} \\
(\%)\end{array}$ & $\begin{array}{l}\text { exo ee } \\
(\text { endo ee })^{c} \\
(\%)\end{array}$ \\
\hline 1 & $\mathrm{HBF}_{4}$ & $95: 5 \mathrm{MeOH}: \mathrm{H}_{2} \mathrm{O}$ & 67 & $52 / 48$ & $91(91)$ \\
\hline 2 & $\mathrm{HBF}_{4}$ & neat $\left(+7\right.$ equiv. $\left.\mathrm{H}_{2} \mathrm{O}\right)$ & 43 & $55 / 45$ & 77 (76) \\
\hline $3^{d}$ & $\mathrm{HBF}_{4}$ & $95: 5 \mathrm{MeOH}: \mathrm{H}_{2} \mathrm{O}$ & 87 & $53 / 47$ & $90(89)$ \\
\hline $4^{e}$ & $\mathrm{HBF}_{4}$ & $95: 5 \mathrm{MeOH}: \mathrm{H}_{2} \mathrm{O}$ & 41 & $55 / 45$ & $93(93)$ \\
\hline 5 & $\mathrm{HBF}_{4}$ & $85: 15 \mathrm{MeOH}: \mathrm{H}_{2} \mathrm{O}$ & 68 & $53 / 47$ & $91(91)$ \\
\hline 6 & $\mathrm{HBF}_{4}$ & $65: 35 \mathrm{MeOH}: \mathrm{H}_{2} \mathrm{O}$ & 81 & $52 / 48$ & $91(91)$ \\
\hline 7 & $\mathrm{HBF}_{4}$ & $\mathrm{MeOH}$ & 31 & $53 / 47$ & $90(91)$ \\
\hline 8 & $\mathrm{HBF}_{4}$ & $95: 5 \mathrm{DCM}: \mathrm{H}_{2} \mathrm{O}$ & 15 & $52 / 48$ & $83(71)$ \\
\hline 9 & $\mathrm{HBF}_{4}$ & $50: 50$ DCM : $\mathrm{H}_{2} \mathrm{O}$ & 65 & $\mathbf{5 0} / \mathbf{5 0}$ & $91(95)$ \\
\hline 10 & $\mathrm{HBF}_{4}$ & $\mathrm{H}_{2} \mathrm{O}$ & 95 & $52 / 48$ & $92(91)$ \\
\hline $\mathbf{1 1}^{d}$ & $\mathrm{HBF}_{4}$ & $\mathrm{H}_{2} \mathrm{O}$ & 98 & $52 / 48$ & $91(90)$ \\
\hline
\end{tabular}

${ }^{a}$ Reaction run at $0{ }^{\circ} \mathrm{C} .{ }^{b}$ Yields determined after chromatographic purification; diastereoisomeric ration determined by NMR on the crude reaction mixture. ${ }^{c}$ Enantiomeric excess determined by HPLC. ${ }^{d}$ Reaction run at $25{ }^{\circ} \mathrm{C} .{ }^{e}$ Reaction run at $-20^{\circ} \mathrm{C}$. 
Table 3 Recycle of the $\mathrm{HBF}_{4}$ salt of PMHS-supported catalyst 5

\begin{tabular}{|c|c|c|c|c|c|}
\hline Entry $^{a}$ & $\begin{array}{l}\text { Recycles } \\
\text { nr. }\end{array}$ & Solvent & $\begin{array}{l}\text { Yield }^{b} \\
(\%)\end{array}$ & $\begin{array}{l}\text { exo/endo }{ }^{c} \\
(\%)\end{array}$ & $\begin{array}{l}\text { exo ee } \\
(\text { endo ee })^{d} \\
(\%)\end{array}$ \\
\hline 1 & 1 & $\mathrm{H}_{2} \mathrm{O}$ & 95 & $52 / 48$ & $92(91)$ \\
\hline 2 & 2 & $\mathrm{H}_{2} \mathrm{O}$ & 90 & $52 / 48$ & $91(91)$ \\
\hline 3 & 3 & $\mathrm{H}_{2} \mathrm{O}$ & 65 & $52 / 48$ & $81(80)$ \\
\hline 4 & 4 & $\mathrm{H}_{2} \mathrm{O}$ & 21 & $52 / 48$ & n.d. (n.d.) \\
\hline 5 & 1 & $50: 50 \mathrm{DCM}: \mathrm{H}_{2} \mathrm{O}$ & 65 & $50 / 50$ & $91(95)$ \\
\hline 6 & 2 & $50: 50 \mathrm{DCM}: \mathrm{H}_{2} \mathrm{O}$ & 61 & $50 / 50$ & $91(93)$ \\
\hline 7 & 3 & $50: 50 \mathrm{DCM}: \mathrm{H}_{2} \mathrm{O}$ & 18 & $50 / 50$ & $86(87)$ \\
\hline 8 & 1 & $95: 5 \mathrm{CH}_{3} \mathrm{CN}: \mathrm{H}_{2} \mathrm{O}$ & 65 & $55 / 45$ & 92 (93) \\
\hline 9 & 2 & $95: 5 \mathrm{CH}_{3} \mathrm{CN}: \mathrm{H}_{2} \mathrm{O}$ & 60 & $52 / 48$ & $90(92)$ \\
\hline 10 & 3 & $95: 5 \mathrm{CH}_{3} \mathrm{CN}: \mathrm{H}_{2} \mathrm{O}$ & 58 & $52 / 48$ & $90(91)$ \\
\hline 11 & 4 & $95: 5 \mathrm{CH}_{3} \mathrm{CN}: \mathrm{H}_{2} \mathrm{O}$ & 60 & $52 / 48$ & 90 (91) \\
\hline 12 & 5 & $95: 5 \mathrm{CH}_{3} \mathrm{CN}: \mathrm{H}_{2} \mathrm{O}$ & 55 & $52 / 48$ & $90(93)$ \\
\hline 13 & 6 & $95: 5 \mathrm{CH}_{3} \mathrm{CN}: \mathrm{H}_{2} \mathrm{O}$ & 53 & $52 / 48$ & $90(91)$ \\
\hline
\end{tabular}

${ }^{a}$ Reaction run at $0{ }^{\circ} \mathrm{C} .{ }^{b}$ Yields determined after chromatographic purification. ${ }^{c}$ Diastereoisomeric ration determined by NMR on the crude reaction mixture. ${ }^{d}$ Enantiomeric excess determined by HPLC.

( $50 \mathrm{~mL}$ of hexanes per $\mathrm{mL}$ of dichloromethane). The precipitated PMHS-supported catalyst was then isolated by centrifugation and filtration in $85-95 \%$ yield and the organic phase was worked-up to obtain the products. The recovered catalyst was then shortly dried under vacuum to remove traces of solvent and recycled. ${ }^{17}$

The methodology afforded remarkable results both as chemical yield and stereocontrol in water; therefore the recycle of $\mathbf{5}$ in water was studied at first. However already in the third run the catalytic systems showed a diminished chemical efficiency that decreased dramatically in the third recycle. ${ }^{18}$ The same trend was observed working in aqueous dichloromethane (entries 5-7).

Gratifyingly we found that a $95 / 5$ acetonitrile/water mixture was the ideal solvent system to guarantee the recycle of the PMHS-supported catalyst. The tetrafluoroborate salt of $\mathbf{5}$ was reused five times with only marginal loss of chemical activity (yield from $65 \%$ to $53 \%$ ) and with no appreciable decrease of stereo and enantiocontrol, affording both exo and endo isomers with enantioselectivity always higher than $90 \%$. The PMHSsupported MacMillan catalyst $\mathbf{5}$ favorably compares to other immobilized imidazolinones, for which the recycle was realized only on two or three reruns ${ }^{10-13}$ or the observed enantioselectivities were lower than those obtained with the nonsupported MacMillan catalyst (Table 3). ${ }^{14,15}$

In conclusion, it was shown that catalysts derived from PMHSsupported imidazolidinone $\mathbf{5}$ and different acids can be conveniently employed to promote Diels-Alder cycloadditions of $\alpha, \beta$-unsaturated aldehydes with cyclopentadiene. The supported catalysts behaved very similarly to their non-supported counterparts in terms of enantioselectivity.** The immobilization on the polymer greatly simplified the catalyst recovery. Recycling experiments showed that the supported catalyst maintains its stereochemical efficiency for up to five reaction cycles. The use of poly(methyl-hydrosiloxane) as support for the development of recyclable organic catalysts opens interesting perspectives and intriguing possibilities; for example since it is possible to synthesize multifunctional polymers bearing two different organic residues, it could be possible in principle to design novel materials and fine tuning the properties of the polymer-supported chiral catalyst. ${ }^{19}$

MB thanks MIUR (Rome) within the national project "Nuovi metodi catalitici stereoselettivi e sintesi stereoselettiva di molecole funzionali”; JSS thanks the Swiss National Fund for financial support.

\section{Notes and references}

$\S$ Commercial PMHS is available from Aldrich with $M_{n}=1900-3200$. - Typically the Diels-Alder cycloadditions run in the presence of an in situ generated salt led to the products in lower yields and enantioselectivities $10-20 \%$ lower than the corresponding reactions promoted by a preformed salt.

$\|$ For example the cycloaddition promoted by $\mathrm{HBF}_{4}$ salt of $\mathbf{3}$ in the $95 / 5 \mathrm{MeOH} / \mathrm{H}_{2} \mathrm{O}$ mixture at $0{ }^{\circ} \mathrm{C}$ led to the formation of the product in $38 \%$ yield, $55 / 45$ exo/endo ratio, $81 \%$ ee for the exo isomer and $72 \%$ ee for the endo isomer.

** In very preliminary experiments PMHS-supported catalyst 5 showed to be able to efficiently catalyze the enantioselective reduction of $\beta$-methyl cynnamic aldehyde with Hantzsch ester; the results will be reported in due course.

1 P. T. Anastas and J. C. Warner, Green Chemistry: Theory and Practice, Oxford University Press, New York, 1998; See: P. T. Anastas, Green Chemistry Textbook, Oxford University Press, New York, 2004.

2 Handbook of Asymmetric Heterogeneous Catalysts, eds. K. J. Ding and F. J. K. Uozomi, Wiley-VCH, Weinheim, 2008; M. Benaglia, Recoverable and Recyclable Catalysts, ed. M. Benaglia, John Wiley and Sons, 2009; N. Haraguchi and S. Itsuno, Polymeric Chiral Catalyst Design and Chiral Polymer Synthesis, John Wiley \& Sons, 2011.

3 Review: A. F. Trindade and C. A. M. Afonso, Chem. Rev., 2009, 109, 3401-3429.

4 M. Benaglia, A. Puglisi and F. Cozzi, Chem. Rev., 2003, 103, 3401-3429. See also F. Cozzi, Adv. Synth. Catal., 2006, 348, 1367-1390.

$5 \mathrm{M}$. Benaglia, Recoverable organic catalysts, in Recoverable and Recyclable Catalysts, ed. M. Benaglia, John Wiley and Sons, 2009.

6 M. Benaglia, New J. Chem., 2006, 30, 1525-1533.

7 For a review on PMHS see: N. J. Lawrence, M. D. Drew and S. M. Bushell, J. Chem. Soc., Perkin Trans. 1, 1999, 3381-3391. For recent contributions see J. Gajewy, J. Gawronski and M. Kwit, Org. Biomol. Chem., 2011, 9, 3863-3870 and references cited.

8 M. S. DeClue and J. S. Siegel, Org. Biomol. Chem., 2004, 2, 2287-2298.

9 K. A. Ahrendt, C. J. Borths and D. W. C. MacMillan, J. Am. Chem. Soc., 2000, 122, 4243-4244. For a review see: G. Lelais and D. W. C. MacMillan, Aldrichimica Acta, 2006, 39, 79-92.

10 M. Benaglia, G. Celentano, M. Cinquini, A. Puglisi and F. Cozzi, Adv. Synth. Catal., 2002, 344, 149-152. See also: M. Benaglia, G. Celentano, M. Cinquini, A. Puglisi and F. Cozzi, Eur. J. Org. Chem., 2004, 567-573.

11 S. A. Selkälä, J. Tois, P. M. Pihko and A. M. P. Koskinen, Adv. Synth. Catal., 2002, 344, 941-945.

12 T. Mitsudome, K. Nose, T. Mizugaki, K. Jitsukawa and K. Kaneda, Tetrahedron Lett., 2008, 49, 5464-5467.

13 Y. Zhang, L. Zhao, S. S. Lee and J. Y. Ying, Adv. Synth. Catal., 2006, 348, 2027-2031.

14 H. Hagiwara, T. Kuroda, T. Hoshi and T. Suzuki, Adv. Synth Catal., 2010, 352, 909-916.

15 J. Y. Shi, C. A. Wang, Z. J. Li, Q. Wang, Y. Zhang and W. Wang, Chem.-Eur. J., 2011, 17, 6206-6213.

16 While we were working on the manuscript another group described the use of a supported catalyst in water (see ref. 15). However with that silica gel-supported MacMillan catalyst enantioselectivities between $62 \%$ and $81 \%$ were typically observed.

17 Different from the Diels-Alder cycloadditions promoted by PEGsupported catalysts ${ }^{10}$ in which recycling was more efficient if the recycled catalyst was treated in situ with a fresh equimolecular amount of acid before adding the reagents, acid addition resulted in lower yields and stereoselection when applied to the PMHSanchored imidazolinones.

18 Any attempt to maintain the chemical efficiency was unsuccessful; for example the addition of a further equivalent of $\mathrm{HBF}_{4}$ to the recovered catalyst allowed the authors to recycle 5 three times, with erosion of chemical yield (from $98 \%$ to $68 \%$ ) and of stereoselectivity (from $91 \%$ ee to $77 \%$ ee for the exo isomer).

19 For the synthesis of bifunctional polymers resulting in different and tunable physico-chemical properties see ref. 8 . The synthesis of bifunctional PMHS, bearing a chiral imidazolinone and a second organic moiety able to modify the solubility of the polymeric material is already under active investigation in our group. 